\title{
Experimental study of air evaporative cooling process using microporous membranes
}

\author{
Sebastian Englart ${ }^{1, *}$ \\ ${ }^{1}$ Wrocław University of Science and Technology, Faculty of Environmental Engineering, Department \\ of Air Conditioning, Heating, Gas Engineering and Air Protection, ul. Norwida 4/6, 50-373 Wrocław,
}

\begin{abstract}
This article describes the potential use of microporous membranes in evaporative cooling applications for air conditioning. The structure of membrane contractor and the measuring device are described. On the basis of the results of the measurements air cooling effectiveness coefficient has been determined.
\end{abstract}

\section{Introduction}

Evaporative cooling is an air cooling method which uses the heat of vaporization of water. Numerous studies analyzed the possibilities of using the evaporative cooling in various options, to maintain comfort conditions in living quarters and to lower air temperature in industrial facilities [1]. This type of air cooling can be characterized by less energy consumption compared to conventional solutions used in air conditioning [2-10]. The disadvantages of evaporative cooling include dependence on the outside air parameters and the lack of possibility of air drying. In the case of direct cooling (DEC) an additional disadvantage is also a direct contact with water. To avoid direct contact of air with water, Johnson et al. [11] proposed the use of membranes for this process. Such a solution is intended to prevent the passage of bacteria, including Legionella, from water to air. The use of a synthetic membrane, which is a porous, semi-permeable barrier between the liquid and the air, allows for a kind of semi-direct evaporative cooling (SDEC).

Membranes are currently used in various industries for separation processes. They may also be used in heating, ventilation and air conditioning (HVAC) systems for various processes such as air treatment, for example: dehumidification or humidification or the evaporative cooling in question [12-19].

The results of experimental research on air evaporative cooling using the membrane module will be presented later in the article.

\section{Performance indices}

While evaluating and selecting the method of evaporative cooling a few indicators should be taken into account. One of the indicators that can be used to compare devices and

\footnotetext{
*Corresponding author: sebastian.englart@pwr.edu.pl
} 
processes of air evaporative cooling is their effectiveness. Besides the effectiveness criterion, also the energetic aspect of the evaporative cooling is important.

\subsection{Effectiveness}

The evaporative cooling has its limitations resulting from the ability of the air to absorb moisture. Those maximum capabilities are clearly determined by the temperature of the air that is being humidified, the amount of moisture in it and the atmospheric pressure.

The equipment efficiency is determined by the real air cooling effectiveness. The effectiveness of the heat exchange can be defined as a relation of the temperature difference in one of the fluids to the difference of temperatures on the heat exchanger inlet. Thus for the water and air membrane heat exchanger the effectiveness can be represented by the following equation:

$$
\varepsilon_{t w}=\frac{t_{d 1}-t_{d 2}}{t_{d 1}-t_{w 1}}
$$

In the studies [18, 19], where the membrane module was used, the above equation was proposed to determine the effectiveness of the sensible cooling.

In order to compare commercial evaporative coolers the following saturation effectiveness indicator is used [20]:

$$
\varepsilon_{t w b}=\frac{t_{d 1}-t_{d 2}}{t_{d 1}-t_{w b 1}}
$$

For some structural solutions for the evaporative coolers the dew point effectiveness is determined [8]:

$$
\varepsilon_{t d p}=\frac{t_{d 1}-t_{d 2}}{t_{d 1}-t_{d p 1}}
$$

\subsection{Energy efficiency ratio}

The energy effectiveness of cooling equipment can also be determined using the energy effectiveness ratio $(E E R)$. For the complete thermal load the EER indicator is determined as a ratio of the cooling power to the electrical power consumption:

$$
E E R=\frac{Q_{c}}{P}
$$

This indicator is used to compare the efficiency of air conditioning equipment. Taking into account only a drop in the outside air temperature, the cooling power of the direct evaporative cooler can be calculated using the following formula [21]:

$$
Q_{c}=m_{a} c_{p a}\left(t_{d 1}-t_{d 2}\right)
$$

The main energy expenditures associated with the membrane semi-direct evaporative cooling (SDEC) operation result from the air and water transport. Hence, the demand for electrical power for the air transport can be represented by the following formula: 


$$
P_{a}=\frac{m_{a} \Delta p_{m}}{\rho_{a} \eta}
$$

For the water transport pumping system:

$$
P_{w}=\frac{m_{w} \Delta p_{p}}{\rho_{w} \eta}
$$

The total demand for electrical power for the evaporative cooling operation using the membrane module, will amount to:

$$
P=P_{a}+P_{w}
$$

For the direct evaporative coolers Watt [21] proposed the introduction of the following parameter:

$$
U C=\frac{Q_{c}}{t_{d 1}-t_{w b 1}}
$$

The unit cooling $U C$ determines the relation of the sensible heat removed from air to the temperature difference (entering air wet bulb depression). Consequently it becomes possible to eliminate the influence of external weather conditions and to bring the comparison to a common base. Watt [21] also proposed the introduction of evaporative EER indicator to the direct evaporative cooling:

$$
e E E R=\frac{U C}{P}
$$

\subsection{Required parameters of the indoor air}

It is necessary to evaluate the influence of an evaporating cooling device on the quality of the indoor microclimate of the premises. The air parameters (temperature, humidity) obtained by means of the evaporative cooler and the conditions required in the room will determine the applicability of the solution. In the areas intended for permanent human stay, specific temperatures, relative humidity and air speed are required, depending on the season and physical activity of the people. The appropriate air parameters are to ensure thermal comfort of the people using the room. The ASHRAE comfort zone for the summer period [1] is indicated on the psychometric chart (Fig.1).

Skrzyniowska [22] indicates that the optimum values of the indoor air for the summer period are as follows: temperature $18-26^{\circ} \mathrm{C}$, relative humidity $40-60 \%$, maximum air speed of $0.3-0.6 \mathrm{~m} / \mathrm{s}$. The closer range of those values should be determined after taking into account physical activity of the people inside. The limits of air in the ventilated facilities without the possibility of cooling can amount up to $70 \%$ of the relative humidity and 3 to $5^{\circ} \mathrm{C}$ of the temperature above the ambient temperature. In industrial spaces, the air parameters in a room (temperature, relative humidity) will often be subordinated to the technological processes conducted there.

One of the methods for determining the cooling capacity of the environment can be the effective temperature. This is a fictitious temperature to which combinations of temperature, humidity and air speed correspond. Such combinations should give the same feeling of comfort. A fragment of the nomogram for determining effective temperatures, with the marked zone of comfort for the summer period is included in Figure 2. It has been developed on the basis of [22]. 


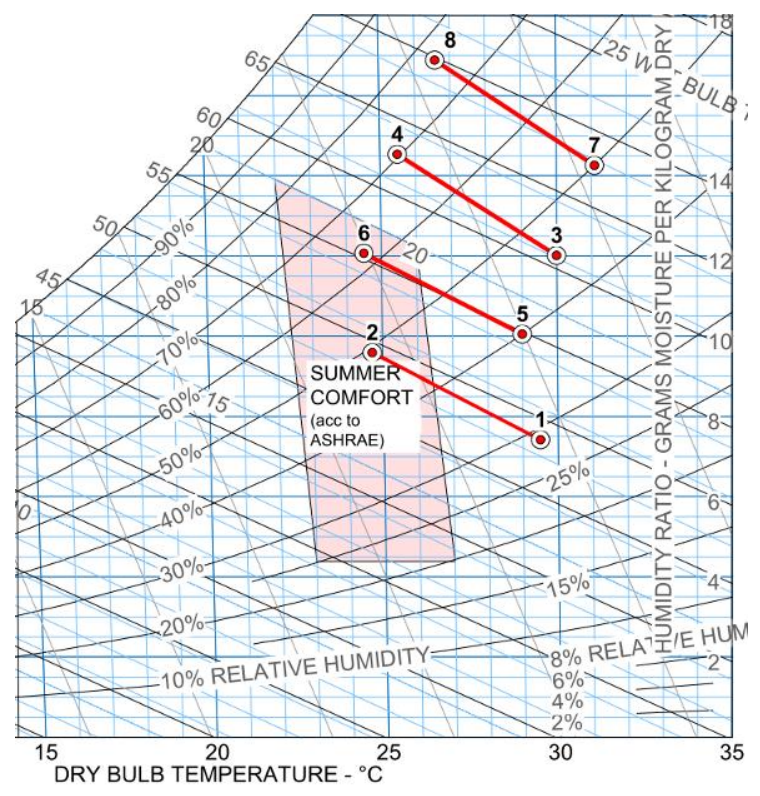

Fig. 1. ASHRAE comfort zone [1] with examples of changes of air in a pilot plant for the semi-direct evaporative cooling.

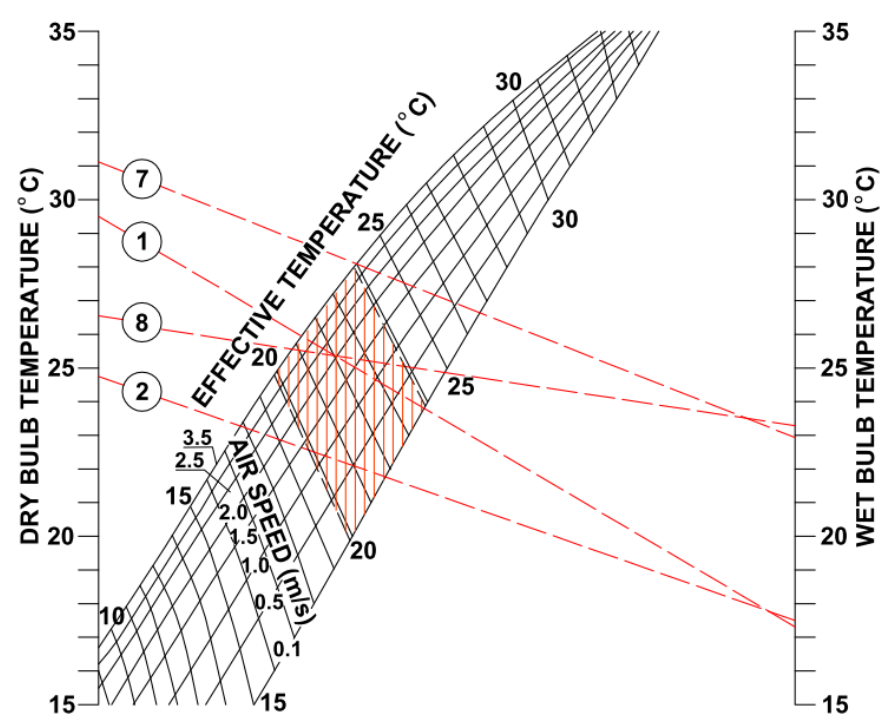

Fig. 2. The cooling capacity of air in the monogram of effective temperatures (developed on the basis of [22]).

\section{Experimental setup}

For the process of semi-direct evaporative cooling (SDEC), a membrane module with a capillary membrane of polypropylene (PP) was used. The parameters of the membrane were as follows: the inner diameter of the membrane of $1.67 \mathrm{~mm}$, the outer diameter of the 
membrane of $2.71 \mathrm{~mm}$, the average pore diameter of $0.43 \mu \mathrm{m}$, the maximum pore size of $0.55 \mu \mathrm{m}$. In the module, 744 membranes of a total surface area of $3.04 \mathrm{~m}^{2}$ and a packing density of $667 \mathrm{~m}^{2} / \mathrm{m}^{3}$ were used. The membranes were situated perpendicularly to the air flow direction (fig. 3).
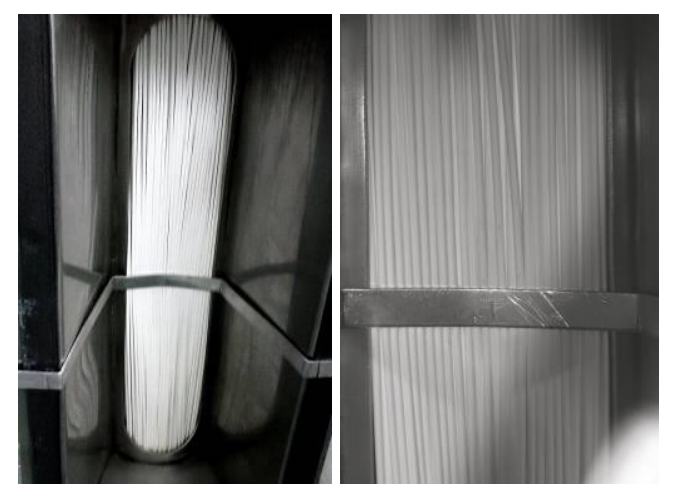

Fig. 3. View of membranes in the module.

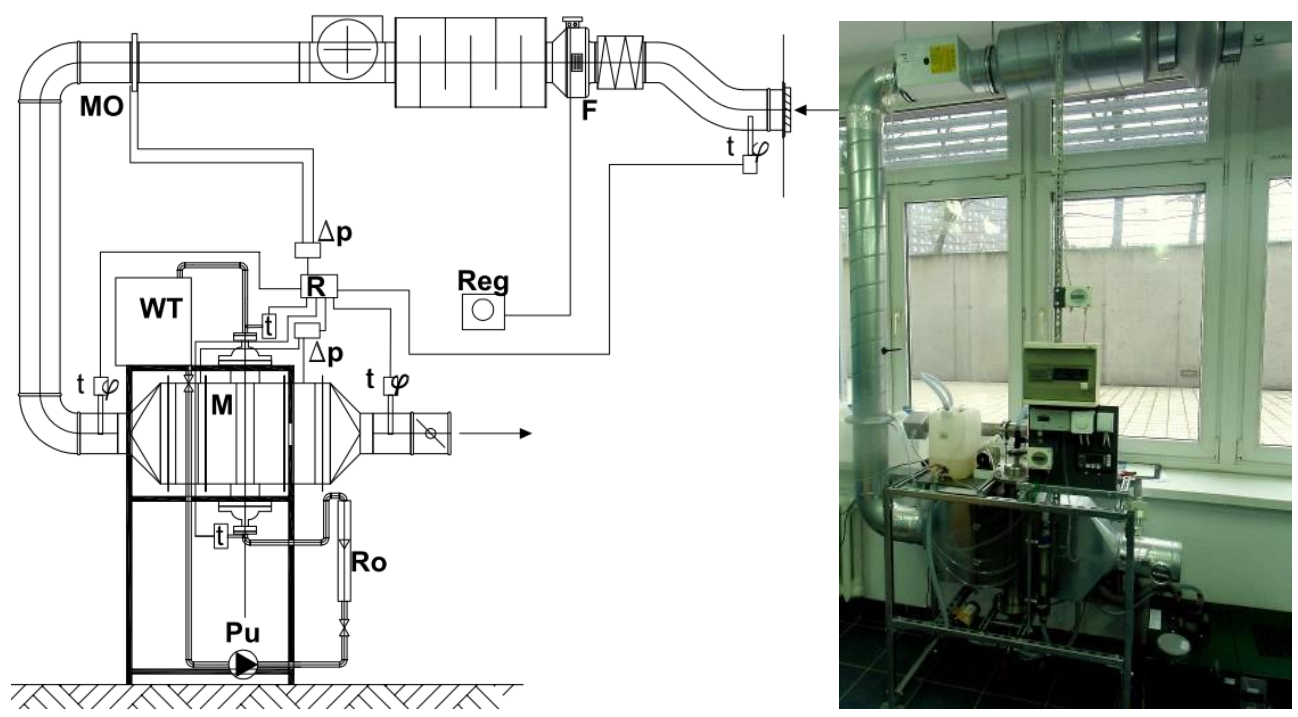

Fig. 4. Schematic diagram and view of the test bench. F-fan, MO-measuring orifice, Ro-rotameter, R-recorder, WT-water reservoir, M-membrane module, Pu-pump, Reg-thyristor controller, sensors of: $\mathrm{t}$ - temperature, $\varphi$ - humidity, $\Delta \mathrm{p}$ - differential pressure.

To evaluate the effectiveness of the evaporative cooling, where the membrane module had been applied the measurements were taken on the test bench which is shown in Figure 4. The measuring bench was equipped with devices for measuring the following parameters:

- outdoor air temperature and humidity,

- air temperature and humidity at the inlet and outlet of the membrane module,

- the air flow rate in the duct,

- temperature of water upstream and downstream the module, 
- the water flow rate.

The measurements were performed at constant flow of air and a variable flow of water. The air flow was $95 \mathrm{~m}^{3} / \mathrm{h}$. The water flow through the internal part of capillaries, forced with a pump, ranged from $50 \mathrm{~kg} / \mathrm{h}$ to $200 \mathrm{~kg} / \mathrm{h}$. The sample air changes obtained in the pilot plant during the tests are shown on the psychometric diagram (Fig. 1). Points 1, 3, 5, 7 determine the air parameters before the module (outside air), points $2,4,6,8$ represent the state of the air after cooling in the membrane module.

\section{Results and discussion}

In the process of semi-direct evaporating cooling which was tested in the module the temperature decreased and the humidity increase simultaneously.

The air changes indicated in Fig. 1 show that the evaporative cooling in the tested unit was insufficient to maintain comfort conditions. After taking into account the potential heat gains in the room, further cooling of the air to the required inlet air temperatures will be necessary. In the case of 1-2, and 5-6 changes, after the application of further cooling, it is possible to obtain the air inlet temperature which ensures thermal comfort without dehumidification. The solution with the initial evaporative cooling can be operated as supportive for conventional air coolers.

In the case of 7-8 changes, it is also possible to obtain a relatively favorable cooling effect related to the effective temperature. Fig. 2 includes the lines presented as numbers $1,2,7,8$, which link the dry and wet bulbs scale. The line numbers correspond to the air parameters before and after the module, according to the numbering of the points in Fig. 1. The intersection of each line between the air speed curves determines the effective temperature for a particular speed. In the case 1 and 2 both the outside air and the cooled air fall within the limits prescribed for the summer period. In the case 7 and 8 the correct effective temperature, on condition that the minimum speed of the air is $1 \mathrm{~m} / \mathrm{s}$, can be obtained only after cooling the air in the membrane module. In the absence of classic air cooling, the use of the semi-direct evaporative cooling may, in some cases, improve the parameters of the air in the room in comparison to other rooms ventilated only with the outside air. Such a solution can be applied to partially improve the microclimate of industrial premises where there is no need to ensure thermal comfort conditions.

The effectiveness $\varepsilon$ were determined based on the equations (1-3). Fig. 5 shows the results obtained for an exemplary measurements series, with respect to the pilot plant operation time. The values obtained are somewhat lower than in the case of classical direct evaporative cooling, but comparable to the processes where the membranes are used [18, 23]. The changes in the rate of water flow through the module, within the range of the stream variation, caused no significant changes in the temperature effectiveness. A similar effect was observed at study [23]. Instead, Johnson et al. [11] proposed resignation from the circulating pump to replace it with the gravitational flow of water into the membrane module.

EER and eEER indicators set by equations (4) and (10) are presented in Fig. 6. The obtained EER for the presented measurement series averaged from 13.6 to 18.5 and the $e E E R$ from 1.10 to 1.41 . With the water flow decreasing, the demand for electric energy for the water pumping decreased, and thus the increase of $E E R$ and $e E E R$ was possible.

In the case of conventional air conditioners the most effective units are characterized by EER of approximately 3.20. According to ASHRAE [1], EER for the two-stage indirect-direct evaporative cooling range between 3.7-11.3. For the analyzed solution Bruno [8] obtained an average value of 11.5 ratio with top temporary values reaching 13 . 


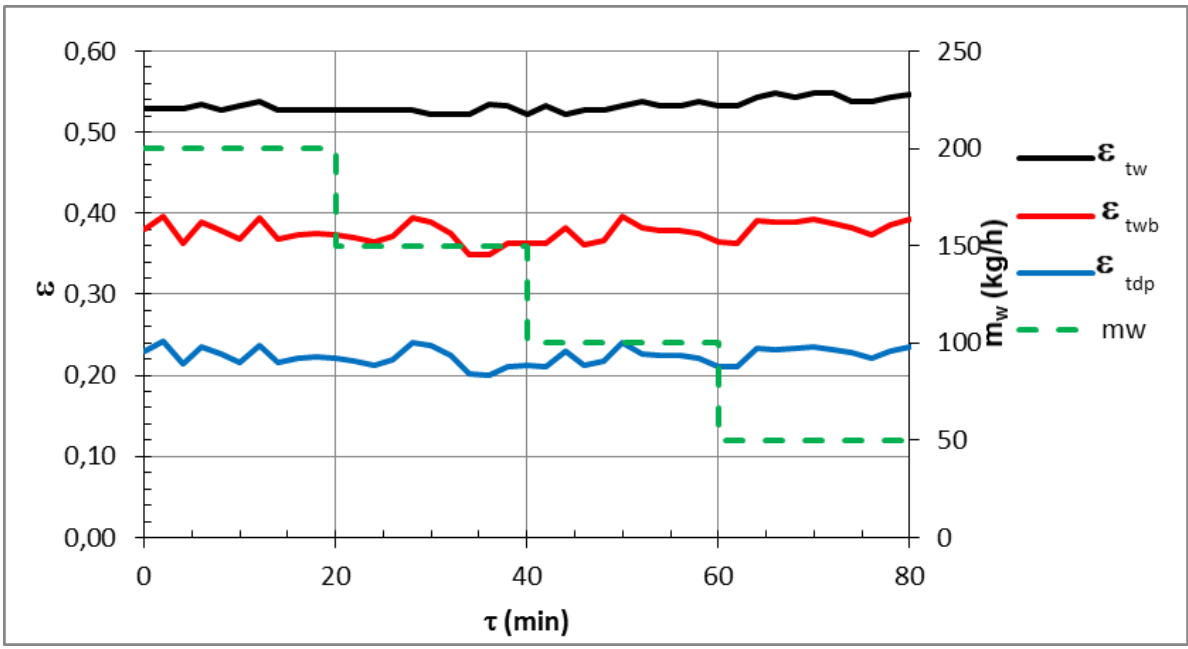

Fig. 5. Changes in the effectiveness and the water flow during the system operation.

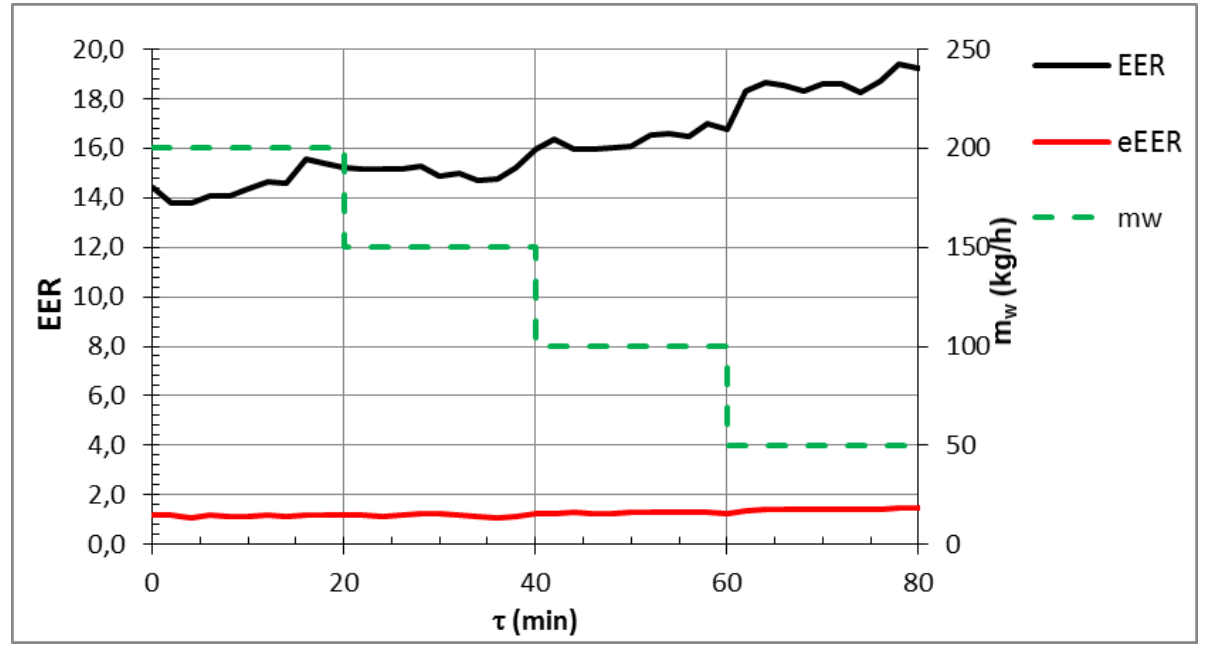

Fig. 6. Changes of $E E R, e E E R$ indicators and the water flow during the system operation.

\section{Conclusions}

In the air conditioning technology drying the air is not always necessary to maintain its appropriate parameters. The semi-direct evaporative cooling results in the increase of air humidity which may limit applicability of the device. The direct evaporative cooling where the membrane module is used can be applied in hot and dry climate conditions. It can also be used as a supportive solution, cooperating with classic solutions, in temperate climates in periods of low relative humidity (approximately 40\%). Moreover the use of the membranes makes it possible to achieve satisfactory temperature coefficient and satisfactory energy effectiveness factors. 


\section{Nomenclature}

$c_{p}-$ specific heat $(\mathrm{J} /(\mathrm{kgK}))$

eEER - evaporative EER $((\mathrm{W} / \mathrm{W}) / \mathrm{K})$

$P$ - total electric power demand (W)

$Q_{c}-$ cooling capacity $(\mathrm{W})$

$\Delta p_{m}$-pressure drop in membrane module $(\mathrm{Pa})$

$\varepsilon$ - effectiveness

$\eta$ - device efficiency

Subscripts:

1 - inlet, 2 - outlet, $a$ - air, $d$-dry bulb, $d p$ - dew point, $w b$ - wet bulb, $w$ - water
$E E R$ - energy efficiency ratio $(\mathrm{W} / \mathrm{W})$

$m$ - mass flow rate $(\mathrm{kg} / \mathrm{s})$

$t$ - temperature $(\mathrm{K})$

$U C-$ unit cooling $(\mathrm{W} / \mathrm{K})$

$\Delta p_{p}$ - pump delivery head $(\mathrm{Pa})$

$\rho-\operatorname{density}\left(\mathrm{kg} / \mathrm{m}^{3}\right)$

\section{References}

1. ASHRAE, Handbook of HVAC Applications (ASHRAE, Atlanta, GA, USA, 2011)

2. G. Heidarinejad, M. Bozorgmehr, S. Delfani, J. Esmaeelian, Build. Environ. 44, 2073-2079 (2009)

3. G. Heidarinejad, M. Heidarinejad, S. Delfani, J. Esmaeelian, Energ. Buildings, 40, 1946-1953 (2008)

4. G. Chiesa, M. Grosso, Build. Environ. 94, 263-272 (2015)

5. J. R. Camargo, C. D. Ebinuma, J. L. Silveira, Int. J. Refrig. 28, 1124-1132 (2005)

6. C. Lertsatitthanakorn, S. Rerngwongwitaya, S. Soponronnarit, Biosyst. Eng. 93, 213-219 (2006)

7. H. Caliskan, I. Dincer, A. Hepbasli, Energ. Buildings 43, 1461-1472 (2011)

8. F. Bruno, Energ. Buildings 43, 3475-3483 (2011)

9. S. Anisimov, D. Pandelidis, J. Danielewicz, Energy 80, 452-464 (2015)

10. H.T. El-Dessouky, H.M. Ettouney, W. Bouhamra, Trans. Inst. Chem. Eng. A 78, 999-1009 (2000)

11. D. W. Johnson, C. Yavuzturk, J. Pruis, J. Membr. Sci. 227, 159-171 (2003)

12. J. Woods, Renew. Sust. Energ. Rev. 33, 290-304 (2014)

13. S. Bergero, A. Chiari, Appl. Therm. Eng. 21, 1119-1135 (2001)

14. S. Bergero, A. Chiari, Energ. Buildings, 42, 1976-1986 (2010)

15. S. Bergero, A. Chiari, Energy 36, 5261-5273 (2011)

16. C. Isetti, E. Nannei, A. Magrini, Energ. Buildings 25, 185-193 (1997)

17. N. T. Charles, D. W. Johnson, J. Membr. Sci. 319, 44-53 (2008)

18. L.Z. Zhang, Z.X. Li, T.S. Zhong, L.X. Pei, J. Membr. Sci. 427, 1-9 (2013)

19. L.Z. Zhang, Int. J. Heat. Mass. Tran. 55, 5861-5869 (2012)

20. L.Z. Zhang, Energy 31, 1228-1242 (2006)

21. J. R. Watt, Evaporative Air Conditioning Handbook (Chapman and Hall, New York, 1986)

22. D. Skrzyniowska, Cz. T. Environment Engineering 28, 3, 15-35 (2012)

23. L.Z. Zhang, S.M. Huang, Int. J. Heat. Mass. Tran. 54, 1055-1063 (2011) 